\title{
Porphyrins and Phthalocyanines as Chromogenic Anion Sensors
}

\author{
João M. M. Rodrigues ${ }^{a}$, Eliana F. A. Carvalho ${ }^{a}$, Andreia S. F. Farinha ${ }^{a}$, Filipe A. \\ Almeida Paz ${ }^{b}$, Augusto C. Toméa ${ }^{a}$, José A. S. Cavaleiro ${ }^{a}$, Jonathan L. Sessler ${ }^{c}$, \\ João P. C. Tomé $\mathrm{a}^{*}$ \\ ${ }^{a}$ QOPNA and ${ }^{b}$ CICECO, Department of Chemistry, University of Aveiro, 3810-193 Aveiro, Portugal;
}

${ }^{c}$ Department of Chemistry and Biochemistry, The University of Texas at Austin, Austin, TX 78712-0165, USA

*jtome@ua.pt

Keywords: Porphyrins, Phthalocyanines, Anion, Chemosensors

\section{INTRODUCTION}

Human activities, such as food and energy production, are responsible for major biological and chemical pollution hazards, including high levels of pathogenic microorganisms, antibiotics, pesticides and anthropogenic anions.

Porphyrins (Por) and phthalocyanines $(\mathrm{Pc})$ possess unique physico-chemical properties which make them valuable compounds in different scientific fields, namely in medicine, catalysis, solar energy converters, etc. ${ }^{2}$ Recently, we have found that Por and $\mathrm{Pc}$ can be used as scaffolds to prepare novel chromogenic anion-binding agents that can be used to build functional materials capable of removing anionic pollutants from contaminated water. New chemosensors capable of sensing targeted guests via changes in their optical properties have attracted considerable attention due to their potential applications in the development of analytical devices. Species capable of selectively recognizing anionic substrates are of interest due to their importance in areas as diverse as nuclear waste treatment, environmental chemistry, and biology. The design of chemosensor materials thus represents an important field of research in organic chemistry. At present interest in such systems is increased due to a need to find, inter alia, methods for waste treatment. Ideally, artificial anion chemosensors should have an ability to selectively recognize and sense anionic analytes using naked eye detectable color changes, or via an easy-tomonitor electrochemical or spectroscopic response. ${ }^{3}$

\section{RESULTS AND DISCUSSION}

Several Por and $\mathrm{Pc}$ bearing multi-NH groups have been synthesized and tested as anion sensors. The anion binding studies were conducted by UV-Vis spectroscopy using several anions, such as fluoride, bromide, acetate, nitrate, nitrite and dihydrogen phosphate, all in the form of tetrabutylammonium salts, in various solvents. For example, upon addition of fluoride or dihydrogen phosphate to a solution of the tested porphyrins, the UV-Vis spectra show a clear reduction of the intensity of their Soret bands (Fig. 1a).

The anion studies with $\mathrm{Pc}$ solutions, showed a significant variation of their UV-Vis spectrum (Fig. 1b) with clear colour modifications with almost all studied anions. The absence of a precise isosbestic point indicates a multiple complexation phenomenon.
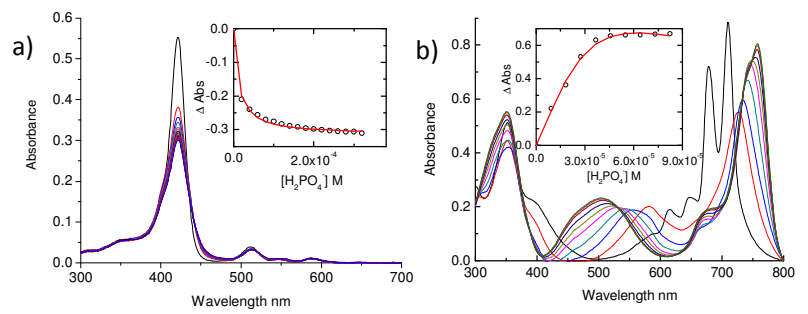

Figure 1. Results of titration experiments carried out with Por (a) and $\mathrm{Pc}(\mathrm{b})$ sensors with $\mathrm{H}_{2} \mathrm{PO}_{4}{ }^{-}$.

\section{CONCLUSION}

These works show clearly that Por and Pc can be used as templates for novel chromogenic binding agents, with high affinity constants.

\section{ACKNOWLEDGEMENTS}

Thanks are due to FCT and FEDER for funding the QOPNA and CICECO research units, and projects PTDC/QUI/65228/2006 \& PTDC/CTM/101538/2008, and the National Institutes of Health (grant GM 58907 to J.L.S.) for financial support. J.M.M.R. (BI/UI51/4489/2010), E.F.A.C. (BI/UI55/4095/2010) and A.S.F.F. (SFRH/BPD/73060/2010) also thank FCT for their corresponding $\mathrm{BI}$ and post-doc grants.

\section{REFERENCES}

${ }^{1}$ C. Lee, H. Miyaji, D. Yoon, J. L. Sessler, Chem. Commun. 2008, 24.

2.The Porphyrin Handbook, Kadish K.M., Smith K.M., Guilard R. (Eds), Academic Press, New York, 2000 (vol. 1-10) and 2003 (vol. 11-20).

S. Xu, K. Chen, H. Tian, J. Mater. Chem. 2005, 15, 2676.

$14^{\text {th }}$ Brazilian Meeting on Organic Synthesis $-14^{\text {th }}$ BMOS - September 01-05, 2011-Brasilia, Brazil 